\title{
An AC-link Bidirectional DC-DC Converter with Synchronous Rectifier
}

\author{
Toshiro Hirose ${ }^{*, * *}$, Keisuke Nishimura ${ }^{* *}$, Takayuki Kimura ${ }^{* *}$, Hirofumi Matsuo ${ }^{* *}$ \\ ${ }^{*}$ Nishimu Electronics Industries Co., Ltd., Saga, 842-0032, Japan \\ ${ }^{* *}$ Nagasaki University, Nagasaki, 852-8521, Japan \\ hirose@nishimu.co.jp
}

\begin{abstract}
This paper describes the principles and characteristics of a novel ac-link bidirectional DC-DC converter with synchronous rectifier, which has a mechanism formed from two bridge-type DC converters that are linked through superposition in additive polarity in series. For an isolated dual active bridge DC-DC converter, which has been studied for many years, the rated voltage of its switching elements is decided according to DC power source voltage and load current. Therefore, as the voltage and current specifications of a converter become higher, physical size becomes larger, conduction and switching losses increase and power efficiency reduces. To solve this problem, the authors devised a unique converter capable of lowering the rated voltage of switching elements, by means of sharing DC power source voltage and load current between two converters. The capacity of the high frequency transformer becomes small, making converter downsizing possible. In addition, further efficiency improvement is facilitated by using MOSFET as switching elements, which have the feature of synchronous rectification. We designed and constructed a $1 \mathrm{~kW}$ converter system in which these advancements were incorporated, and conducted evaluation testing to verify the conversion efficiency and transient property. The results of testing demonstrated that this DC-DC converter had a conversion efficiency of $98.2 \%$ at the rated $1 \mathrm{~kW}$, as well as very stable transient operation. A detailed analysis of power flow was also carried out, to identify the characteristics of the converter developed.
\end{abstract}

\section{INTRODUCTION}

The isolated dual active bridge DC-DC converter, which has been studied for many years, was initially applied as a soft-switching-converter to meet the requirements of large power [1]. For conversion efficiency improvement, its use as a resonant-type converter by equipping it with snubber capacitance [2], as well as use of silicon carbide ( $\mathrm{SiC}$ ) power devices and new magnetic materials, is currently being proposed [3]. In addition, various converter usages, such as for charge/discharge of batteries mounted on fuel cell electric vehicles [4]-[6], and energy charge/discharge systems [7] to regulate power fluctuations that impact renewable energy based power generation systems, are being strategically studied. In power generation systems using natural energy, which is nowadays highlighted, bi-directional DC-DC converters have been commonly used to maintain system stability under the charge/discharge control of secondary batteries and electric double-layer capacitors. Such existing DC-DC converters are characterized by a bidirectional power flow between different voltages [8]. Thus, in the case that high voltage, high current specifications are required, DC-DC converters need to be large in size, resulting in a reduction in power efficiency due to an increase in conduction and switching losses.

To solve this problem, the authors proposed an ac-link bidirectional DC-DC converter equipped with a synchronous rectification function. The proposed converter system, which has a mechanism formed from two bridge-type DC converters that are linked through superposition in additive polarity in series, is capable of lowering the rated voltage of switching elements, by means of sharing the voltage of DC power source and the load current on the high-voltage side between the two converters [9], [10]. The capacity of the high frequency transformer becomes small, making the converter more efficient and smaller in size. In addition, further efficiency improvement is facilitated by using MOSFET as switching elements, which have a feature of synchronous rectification. Fig. 1 shows the circuit diagram of a bidirectional isolated dual active bridge DC-DC converter, which has previously been researched, and Fig. 2 shows the circuit diagram of our proposed converter.

In Fig. 1 , converter 1 is set on the low-voltage side, while converter 2 is set on the high-voltage side. The input and output power circuits are generally isolated; however, this conventional converter has problems in that 1) the rated current of converter 1 switching elements are controlled by the DC current $\left(i_{D I}\right)$, causing a high-current condition; and 2) the rated voltage of converter 2 switching elements are controlled by voltage $\left(V_{0}\right)$ on the high-voltage side, causing a high-voltage condition. Thus, it results in necessity of a converter capable of tolerating high-current and high-voltage.

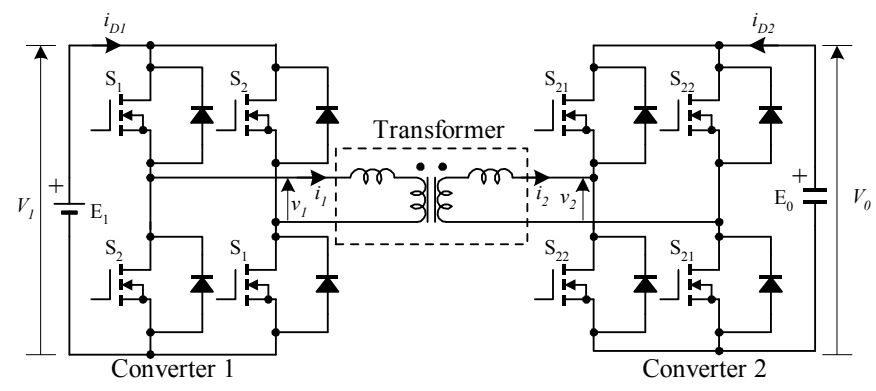

Fig. 1. Bidirectional isolated dual active bridge DC-DC converter. 


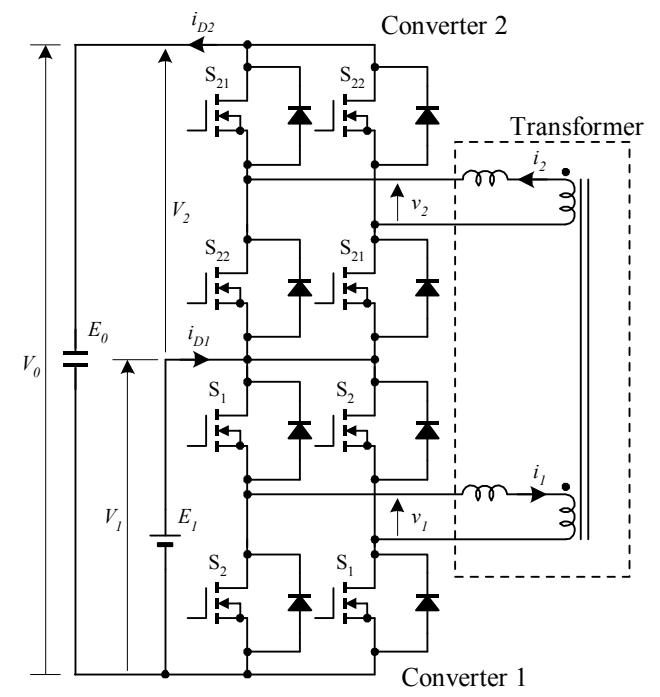

Fig. 2. AC-link bidirectional DC-DC converter with synchronous rectifier.

In contrast, the proposed converter has no function to isolate the input and output power circuits; however, it has the following beneficial characteristics:

1) The voltage $\left(V_{0}\right)$ of the DC power source on the highvoltage side $\left(E_{0}\right)$ can be shared by converters 1 and 2 based on the transformer winding turns ratio. For instance, when the turns ratio between primary coil and secondary coil is $1: 1$, the rated voltage of switching elements of converters 1 and 2 is half of $V_{0}$, contributing to the lowering of the switching element voltage rating.

2) The current $\left(i_{D I}\right)$ passing through the DC power source on the low-voltage side $\left(E_{l}\right)$ can be shared by converters 1 and 2 based on the transformer winding turns ratio. For instance, when the turns ratio is $1: 1$, the rated current of switching elements of converters 1 and 2 is half of $i_{D l}$, contributing to the lowering of the switching element current rating.

3) Through mechanisms 1) and 2), the rated capacity to be processed by the high frequency transformer is decreased by half, contributing to downsizing as well as loss reduction.

4) Zero-current switching (ZCS) and zero-voltage switching (ZVS) are realized under a wide operation range when all switching elements are turned on, resulting in high efficiency.

\section{OPERATION MODE OF THE PROPOSED DC-DC CONVERTER}

Power flow from DC power source on the low-voltage side $\left(E_{l}\right)$ toward DC power source on the high-voltage side $\left(E_{0}\right)$ is defined as power running mode, while the opposite power flow is defined as power regenerative mode. Fig. 3 shows the transformer primary current waveforms at the time of the proposed DC-DC converter switching operation in power running mode. In contrast, for power regenerative mode, similar waveforms can be achieved by reversing the phase

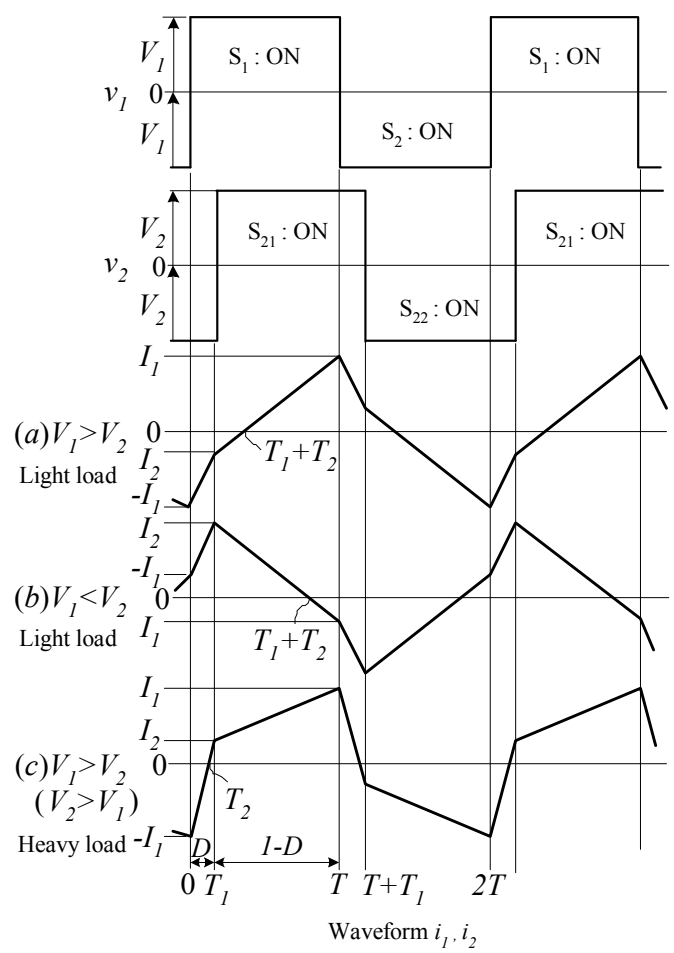

Fig. 3. Transformer primary and secondary current waveforms in power running mode.

difference between the transformer primary voltage $\left(v_{l}\right)$ and transformer secondary voltage $\left(v_{2}\right)$. The transformer winding turns ratio is set at 1:1. An individual converter is driven in one-pulse mode without controlling pulse width. The on-duty ratio between $S_{1}$ and $S_{2}$, as well as that between $S_{21}$ and $S_{22}$, is $50 \%$. Depending on the magnitude of current transmitted, as well as magnitudes of DC voltages $\left(V_{1}, V_{2}\right)$, each waveform of transformer primary current $\left(i_{l}\right)$ and transformer secondary current $\left(i_{2}\right)$ has three patterns, respectively; that is, patterns $(a),(b)$ and $(c)$, as shown in Fig. 3. In the case of pattern $(c)$, turn-on of all switching elements occurs under the condition of ZCS and ZVS, because the anti-parallel diode is in on-state. In contrast, the hard-turn-on phenomenon occurs in particular switching elements; that is, $\mathrm{S}_{21}$ and $\mathrm{S}_{22}$ in pattern $(a), \mathrm{S}_{1}$ and $\mathrm{S}_{2}$ in pattern $(b)$.

\section{OPERATING ANALYSIS}

In the case of pattern $(a)$ in power running mode, states that emerged in the time periods $0 \sim T_{1}, T_{1} \sim T_{1}+T_{2}, T_{1}+T_{2} \sim T$ are defined as states 1,2 and 3 , respectively. To analyze power flow, we set up circuits equivalent to these states as shown in Fig. 4, and obtained MOSFET device models by applying the method of approximation, as shown in Fig. 5. Using the converter circuit parameters listed in Table 1, transformer primary current $\left(i_{1}\right)$ was obtained from numerical calculations. 


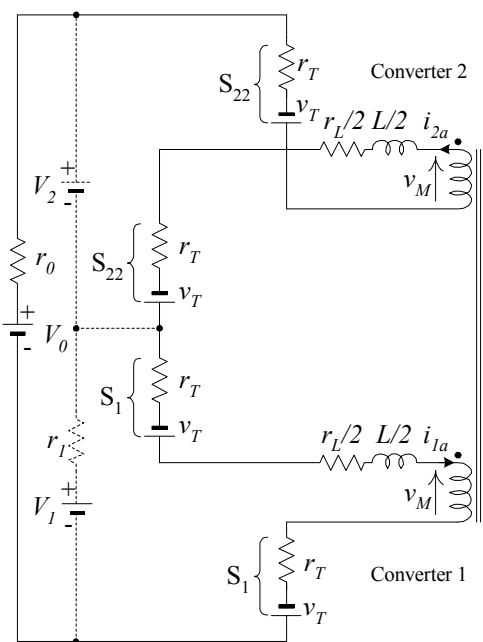

State 1

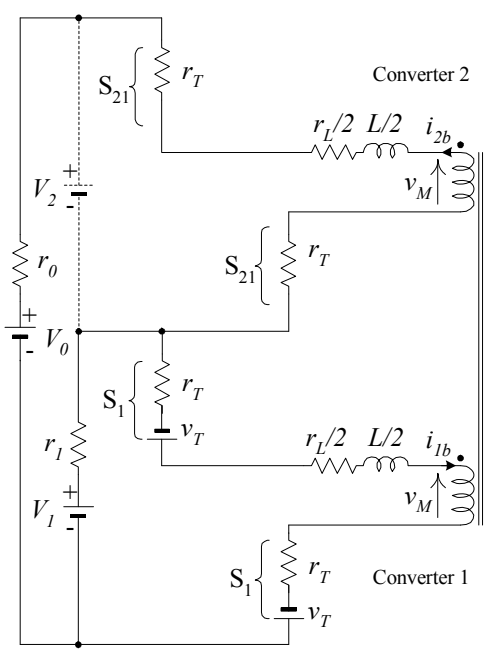

State 2

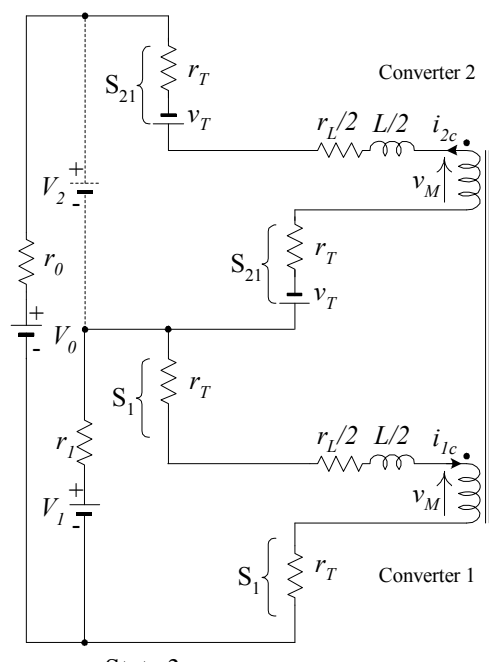

State 3

Fig. 4. Current flows and equivalent circuits.

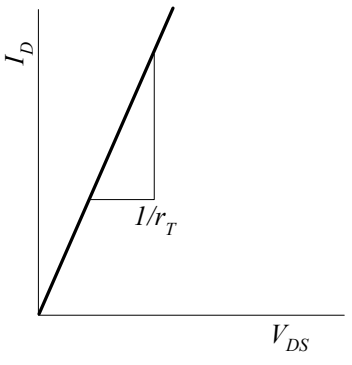

Switching device mode ( $\mathrm{I}_{\mathrm{D}}$ forward current)

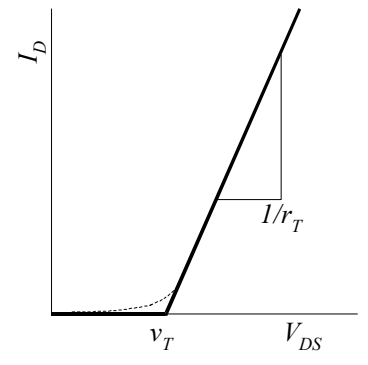

Switching device model

( $\mathrm{I}_{\mathrm{D}}$ reverse current)
Fig.5. MOSFET device models.

\section{A. State analysis}

1) State $1\left(t=0 \sim T_{l}\right)$

$\mathrm{S}_{1}$ is turned on under the condition of $i_{1 a}=i_{2 a}=-I_{l}$ when $t=$ 0 , and then state 1 starts. At this time, diodes in an antiparallel connection with $\mathrm{S}_{1}$ are already in a turn-on condition. Since directions of current flows $\left(i_{1 a}, i_{2 a}\right)$ do not change rapidly, $i_{1 a}$ flows to FET of $\mathrm{S}_{1}$, and $i_{2 a}$ flows to FET of $\mathrm{S}_{22}$. Current does not flow to DC power source $\left(E_{l}\right)$. The following two Laplace transform equations are given by the equivalent circuit of state 1 shown in Fig. 4. Default values of $i_{1 a}$ and $i_{2 a}$ are set as $-I_{1}$.

$$
\begin{aligned}
\frac{V_{0}}{s} & =\left(\frac{L s+r_{L}}{2}+2 r_{T}+r_{0}\right) I_{2 a}(s)-\frac{2 v_{T}}{s}+\frac{L I_{1}}{2} \\
& -V_{M}(s)+\frac{V_{1}}{s} \\
\frac{V_{1}}{s} & =\left(\frac{L s+r_{L}}{2}+2 r_{T}\right) I_{1 a}(s)-\frac{2 v_{T}}{s}+\frac{L I_{1}}{2}+V_{M}(s)
\end{aligned}
$$

Since $i_{1 a}=i_{2 a}$, (3) is obtained from both (1) and (2).

$$
\begin{aligned}
I_{1 a}(s) & =I_{2 a}(s)=\frac{V_{0}+4 v_{T}-L I_{1} s}{L s\left(s+\frac{r_{L}+r_{0}+4 r_{T}}{L}\right)} \\
& =\frac{\frac{V_{1 a}}{r_{a}}}{s}-\frac{\frac{V_{1 a}}{r_{a}}+I_{1}}{s+\frac{r_{a}}{L}}
\end{aligned}
$$

Here, (4) is obtained from the following equations.

$$
\begin{aligned}
& r_{a}=r_{L}+r_{0}+4 r_{T} \quad, \quad V_{1 a}=V_{0}+4 v_{T} \\
& i_{1 a}(t)=i_{2 a}(t)=\frac{V_{1 a}}{r_{a}}-\left(\frac{V_{1 a}}{r_{a}}+I_{1}\right) e^{-\frac{r_{a}}{L} t}
\end{aligned}
$$

Further, when the current is defined as $I_{2}$ at time $T_{1}$, and $T_{1} / T=D$, (5) is obtained from (4).

$$
e^{-\frac{\pi r_{a}}{\omega L} D}=\frac{\frac{V_{1 a}}{r_{a}}-I_{2}}{\frac{V_{1 a}}{r_{a}}+I_{1}}
$$

\section{2) State $2\left(t=T_{1} \sim T_{1}+T_{2}\right)$}

$\mathrm{S}_{21}$ is turned on when $t=T_{1}$ after $\mathrm{S}_{22}$ is turned off, and reverse recovery current flows until reverse recovery for diodes of $\mathrm{S}_{22}$ is completed, which causes DC voltage $\left(V_{2}\right)$ to short-circuit. In this case, the hard-turn-on phenomenon of $\mathrm{S}_{21}$ occurs. However, this phenomenon emerges in the light load period, resulting in only a minor switching loss. In the case of 
pattern $(c)$ in power running mode, when $S_{21}$ is turned on under the condition that diodes of $\mathrm{S}_{21}$ are in on-state, resulting in the condition of ZCS and ZVS. In this mode, current of $i_{1 b}$ $+i_{2 b}$ flows to DC power source $\left(E_{l}\right)$. The following two Laplace transform equations are given by the equivalent circuit of state 2 shown in Fig. 4. Default values of $i_{l a}$ and $i_{2 a}$ are set as $I_{2}$.

$$
\begin{aligned}
\frac{V_{0}}{s}= & -r_{1}\left\{I_{1 b}(s)+I_{2 b}(s)\right\}-\left(\frac{L s+r_{L}}{2}+2 r_{T}+r_{0}\right) I_{2 b}(s) \\
& +\frac{L I_{2}}{2}+V_{M}(s)+\frac{V_{1}}{s} \\
\frac{V_{1}}{s} & =r_{1}\left\{I_{1 b}(s)+I_{2 b}(s)\right\}+\left(\frac{L s+r_{L}}{2}+2 r_{T}\right) I_{1 b}(s) \\
& -\frac{2 v_{T}}{s}-\frac{L I_{2}}{2}+V_{M}(s)
\end{aligned}
$$

Since $i_{1 b}=i_{2 b,}$ (8) is obtained from (6) and (7).

$$
\begin{aligned}
I_{1 b}(s)= & I_{2 b}(s)=\frac{2 V_{1}-V_{0}+2 v_{T}+L I_{2} s}{L s\left(s+\frac{r_{L}+4 r_{T}+r_{0}+4 r_{1}}{L}\right)} \\
= & \frac{\frac{V_{1 b}}{r_{b}}}{s}-\frac{\frac{V_{1 b}}{r_{b}}-I_{2}}{s+\frac{r_{b}}{L}}
\end{aligned}
$$

Here, (9) is obtained from the following equations.

$$
\begin{gathered}
r_{b}=r_{L}+4 r_{T}+r_{0}+4 r_{1} \quad, \quad V_{1 b}=2 V_{1}-V_{0}+2 v_{T} \\
i_{1 b}(t)=i_{2 b}(t)=\frac{V_{1 b}}{r_{b}}-\left(\frac{V_{1 b}}{r_{b}}-I_{2}\right) e^{-\frac{r_{b}}{L} t}
\end{gathered}
$$

Further, when the current is defined as zero at time $T_{1}+T_{2}$, (10) is obtained from (9).

$$
e^{\frac{\pi r_{b} T_{2}}{\omega L T}}=1-\frac{r_{b}}{V_{1 b}} I_{2}
$$

\section{3) State $3\left(t=T_{1}+T_{2} \sim T\right)$}

The magnetic energy of leakage inductance diminishes when $t=T_{1}+T_{2}$. The reverse current flowing to FET of $\mathrm{S}_{1}$ is turned to flow forward though FET of $S_{1}$ under the condition of ZCS and ZVS. As in the case of state 1, the following two Laplace transform equations are given by the equivalent circuit of state 3 shown in Fig. 4 . The default values of $i_{l c}$ and $i_{2 c}$ are set as zero.

$$
\begin{aligned}
\frac{V_{0}}{s} & =-r_{1}\left\{I_{1 c}(s)+I_{2 c}(s)\right\}-\left(\frac{L s+r_{L}}{2}+2 r_{T}+r_{0}\right) I_{2 c}(s) \\
& -\frac{2 v_{T}}{s}+V_{M}(s)+\frac{V_{1}}{s}
\end{aligned}
$$

$$
\frac{V_{1}}{s}=r_{1}\left\{I_{1 c}(s)+I_{2 c}(s)\right\}+\left(\frac{L s+r_{L}}{2}+2 r_{T}\right) I_{1 c}(s)+V_{M}(s)
$$

Since $i_{1 c}=i_{2 c}$, (13) is obtained from (11) and (12).

$$
\begin{aligned}
I_{1 c}(s) & =I_{2 c}(s)=\frac{2 V_{1}-V_{0}-2 v_{T}}{L s\left(s+\frac{r_{L}+4 r_{T}+r_{0}+4 r_{1}}{L}\right)} \\
& =\frac{\frac{V_{1 c}}{s}}{s}-\frac{\frac{V_{1 c}}{r_{b}}}{s+\frac{r_{b}}{L}}
\end{aligned}
$$

Here, (14) is obtained from the following equations.

$$
\begin{gathered}
r_{b}=r_{L}+4 r_{T}+r_{0}+4 r_{1}, \quad V_{1 c}=2 V_{1}-V_{0}-2 v_{T} \\
i_{1 c}(t)=i_{2 c}(t)=\frac{V_{1 c}}{r_{b}}\left(1-e^{-\frac{r_{b}}{L} t}\right)
\end{gathered}
$$

Further, when the current is defined as $I_{1}$ at time $T,(15)$ is obtained from (14).

$$
I_{1}=\frac{V_{1 c}}{r_{b}}\left(1-e^{-\frac{\pi r_{b}}{\omega L}(1-D)} e^{\frac{\pi r_{b} T_{2}}{\omega L T}}\right)
$$

\section{B. Numerical calculations of AC output current waveforms}

Using the values of $I_{1}$ and $I_{2}$, which are derived from (5), (10) and (15), (16) and (17) can be obtained.

$$
\begin{gathered}
I_{1}=\frac{\frac{V_{1 a}}{r_{a}} \frac{r_{b}}{V_{1 b}}\left(1-e^{-\frac{\pi r_{a}}{\omega L} D}\right) e^{-\frac{\pi r_{b}}{\omega L}(1-D)}+1-e^{-\frac{\pi r_{b}}{\omega L}(1-D)}}{\frac{r_{b}}{V_{1 c}}+\frac{r_{b}}{V_{1 b}} e^{-\frac{\pi r_{a}}{\omega L} D} e^{-\frac{\pi r_{b}}{\omega L}(1-D)}} \\
I_{2}=\frac{\frac{V_{1 a}}{r_{a}} \frac{r_{b}}{V_{1 c}}\left(1-e^{-\frac{\pi r_{a}}{\omega L} D}\right)-\left(1-e^{\frac{\pi r_{b}}{\omega L}(1-D)}\right) e^{-\frac{\pi r_{b}}{\omega L} D}}{\frac{r_{b}}{V_{1 c}}+\frac{r_{b}}{V_{1 b}} e^{-\frac{\pi r_{a}}{\omega L} D} e^{-\frac{\pi r_{b}}{\omega L}(1-D)}}
\end{gathered}
$$

We obtained $I_{1}$ and $I_{2}$ by substituting parameters listed in Table 1 into (16) and (17). Then, numerical calculations were made using (4), (9) and (14) to obtain transformer primary current $\left(i_{1}\right)$. Fig. 6 shows individual waveforms obtained by calculation and experiment in pattern $(a)$ in power running mode. Similar analysis was carried out for patterns $(b)$ and $(c)$, and numerical calculation for transformer primary current $\left(i_{1}\right)$ was made by changing the value of $V_{l}$. Figs. 7 and 8 show the waveforms obtained by calculations and experiments, showing a near coincidence between the two waveforms. 
Table 1 Circuit symbols and parameters

\begin{tabular}{|l|l|l|}
\hline FET threshold voltage & $v_{T}$ & $0.2 \mathrm{~V}$ \\
\hline FET on-resistance & $r_{T}$ & $100 \mathrm{~m} \Omega$ \\
\hline Total resistance of transformer & $r_{L}$ & $100 \mathrm{~m} \Omega$ \\
\hline Internal resistance of low voltage source & $r_{1}$ & $1 \mathrm{~m} \Omega$ \\
\hline Internal resistance of high voltage source & $r_{0}$ & $1 \mathrm{~m} \Omega$ \\
\hline Leakage inductance of transformer & $L$ & $220 \mu \mathrm{H}$ \\
\hline Voltage of transformer & $v_{M}$ & $160 \mathrm{~V}=\mathrm{V}_{0} / 2$ \\
\hline Switching frequency & $f$ & $20 \mathrm{kHz}$ \\
\hline DC voltage on low-voltage side & $V_{1}$ & $160 \mathrm{~V}$ \\
\hline DC voltage on high-voltage side & $V_{0}$ & $320 \mathrm{~V}$ \\
\hline
\end{tabular}
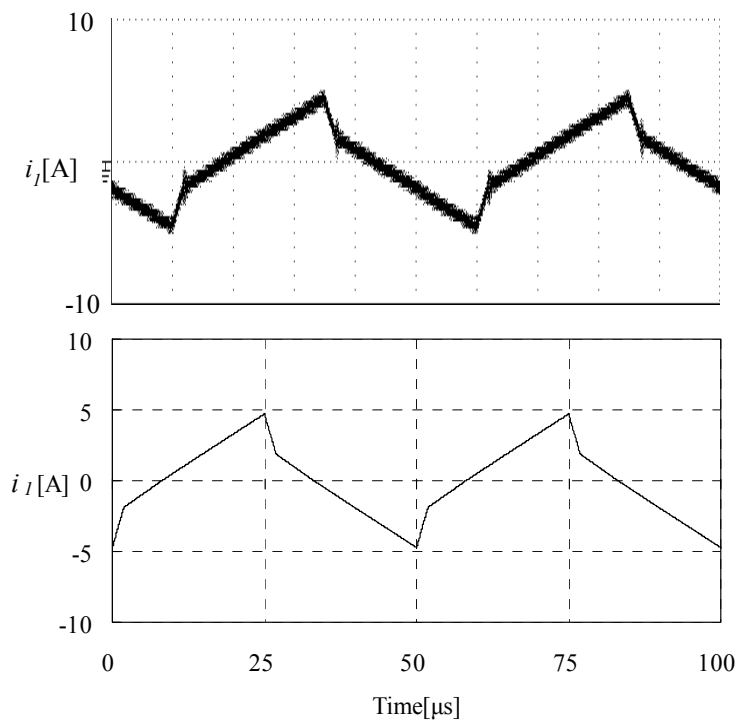

Fig.6. Transformer primary current $\left(i_{1}\right)$ in pattern $(a)$ in power running mode.

Above : Experiment waveform Below : Calculation waveform (input voltage $192 \mathrm{~V}$, output voltage $320 \mathrm{~V}$, output power $500 \mathrm{~W}$ )
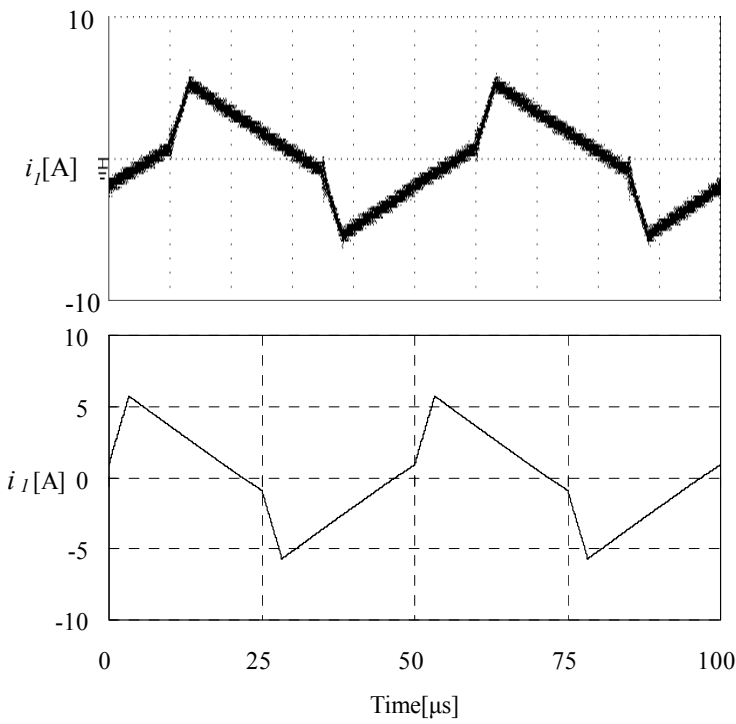

Fig.7. Transformer primary current $\left(i_{1}\right)$ in pattern $(b)$ in power running mode.

Above : Experiment waveform Below : Calculation waveform (input voltage $128 \mathrm{~V}$, output voltage $320 \mathrm{~V}$, output power $500 \mathrm{~W}$ )
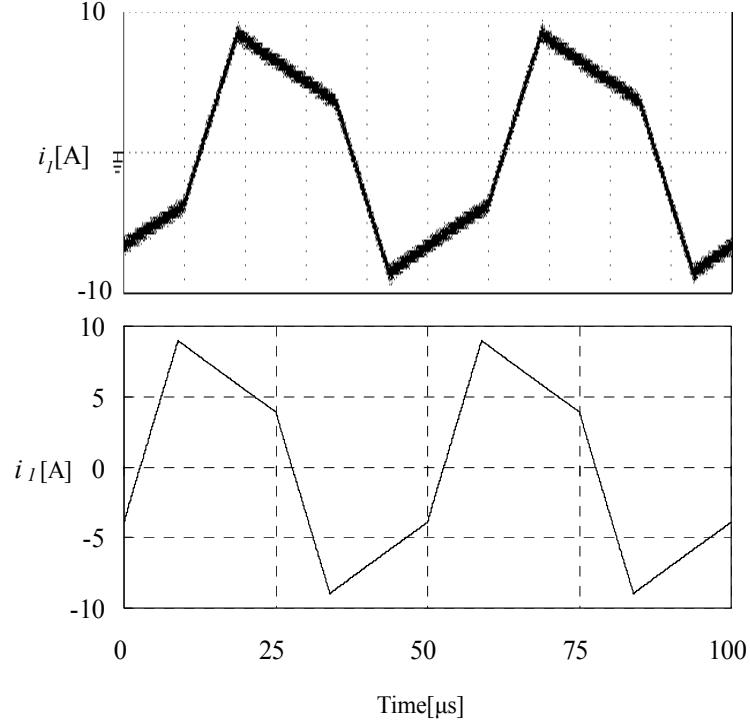

Fig.8. Transformer primary current $\left(i_{1}\right)$ in pattern $(c)$ in power running mode.

Above : Experiment waveform Below : Calculation waveform (input voltage $128 \mathrm{~V}$, output voltage $320 \mathrm{~V}$, output power $1 \mathrm{~kW}$ )

\section{EXPERIMENTAL RESULTS}

We constructed a prototype of the proposed DC-DC converter, with the following specifications: rated output capacity $P_{o}=1 \mathrm{~kW}, V_{I}=160 \mathrm{~V}$, and $V_{0}=320 \mathrm{~V}$. Using the prototype, its conversion efficiency, as well as its output voltage transient property when a steep load fluctuation occurs, was evaluated by testing under PI (proportional integral) control based on the feedback system.

\section{A. Conversion efficiency characteristics of proposed DC-DC converter}

MOSFET, as switching elements that were incorporated into the converters, were connected to fast recovery diodes in reverse parallel. Ferrite was used as the core material for the high frequency transformer, which incorporated a mechanism to enfold leakage inductance.

Fig. 9 shows the circuit used for the converter performance evaluation testing in power running mode. In power regenerative mode, a circuit, in which load, MCB and power source were alternated, was used. Figs.10 and 11 show the current/voltage waveforms at different locations of the proposed converter, which were obtained in the experiment.

Figs. 12 and 13 show the conversion efficiency of this converter, in the case that power source voltage (input side) was changed by the rated value, $-10 \%$ and $-20 \%$, in power running mode and power regenerative mode respectively. Note that power required for control power source is not included in conversion efficiency.

At the rated output of $1 \mathrm{~kW}$, high conversion efficiencies of $98.2 \%$ in both power running mode and power regenerative mode were obtained. When $v_{1}$ is equal to $v_{2}$, high conversion 
efficiency can be maintained even during the light load period. However, the larger the difference between $v_{1}$ and $v_{2}$ is, the lower the conversion efficiency becomes. As shown in Fig. 10 , when $\mathrm{S}_{2}$ was turned on, this caused DC voltage $\left(V_{l}\right)$ to short-circuit, resulting in generation of surge current. Thus, hard-turn-on phenomenon occurs in $\mathrm{S}_{2}$, causing a drop in conversion efficiency.

Fig. 11 shows the current $\left(I_{S 2}\right)$ flowing to $\mathrm{S}_{2}$ was negative immediately before $S_{2}$ was turned on at the time when gate voltage $\left(V_{G S}\right)$ rose. It was found that $I_{S 2}$ flowed to diodes of $\mathrm{S}_{2}$, and $V_{D S}$ of $\mathrm{S}_{2}$ was clamped by the forward voltage of diodes. Thus, the soft-turn-on of $\mathrm{S}_{2}$ occurred under the condition of ZVS and ZCS.

\section{B. Constant voltage output characteristics}

Figs. 14 and 15 show constant voltage output characteristics under feedback control. DSP (TMS320F28335) made by TI (Texas Instruments) was used as controller IC. PI control as a digital control was employed. Operating frequency was set at $90 \mathrm{MHz}$. As a result of experiment, it was demonstrated that a constant voltage control accuracy of $\pm 0.3 \%$ against the rated output voltage could be achieved. This suggests that the proposed converter ensures sufficient constant voltage control accuracy to meet the requirements of power storage devices on the low-voltage side, such as secondary batteries and electric double-layer capacitors.

\section{Output voltage transient property when a steep load fluctuation occurs}

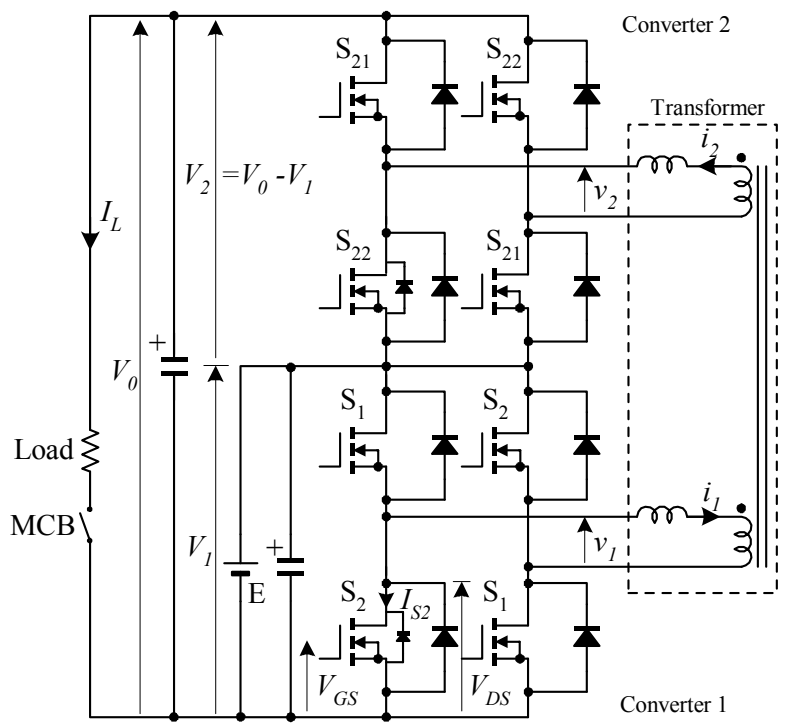

Fig.9. Test circuit for evaluation of converter characteristics.

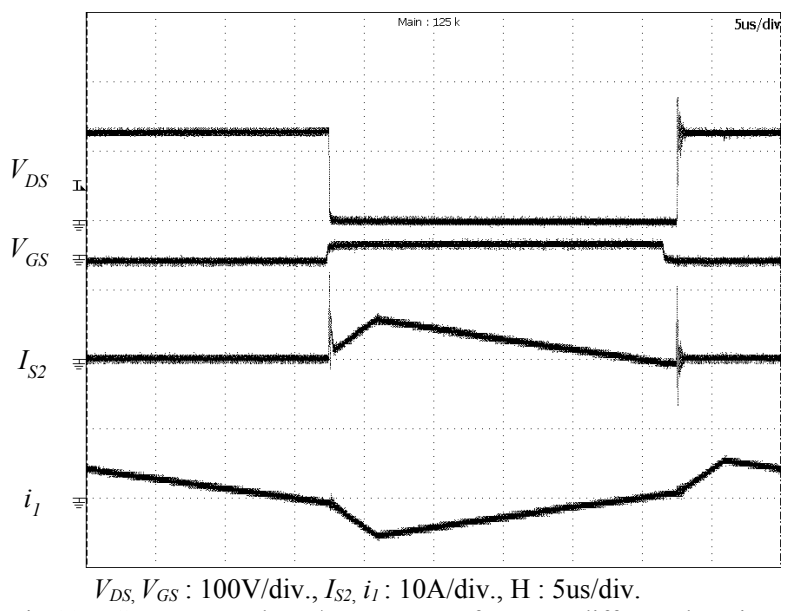

Fig.10. Converter voltage/current waveforms at different locations of converter in power running mode. $\left(V_{l}=128 \mathrm{~V}, V_{0}=320 \mathrm{~V}, P_{0}=500 \mathrm{~W}\right)$

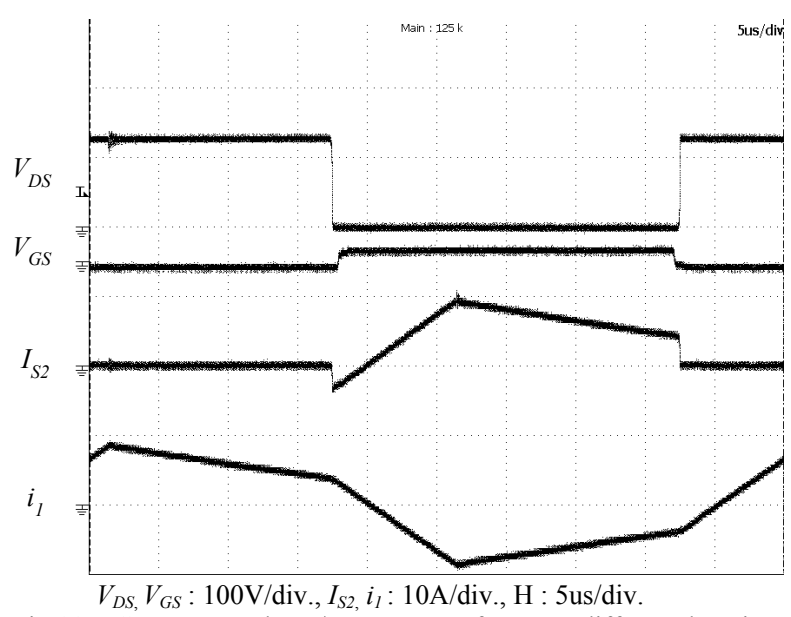

Fig.11. Converter voltage/current waveforms at different locations of converter in power running mode. $\left(V_{1}=128 \mathrm{~V}, V_{0}=320 \mathrm{~V}, P_{0}=1 \mathrm{~kW}\right)$

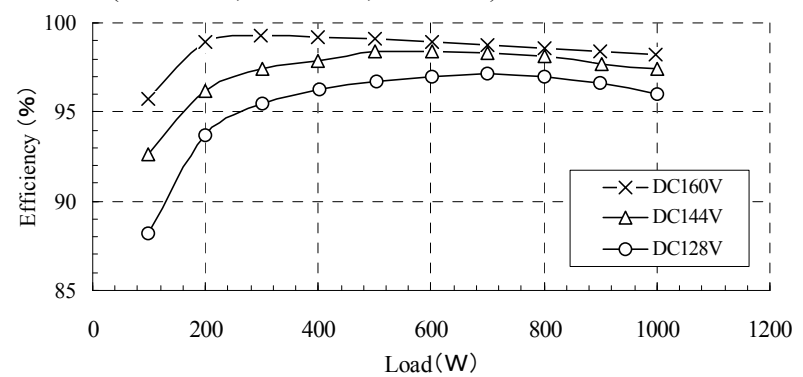

Fig.12. Conversion efficiency in power running mode .

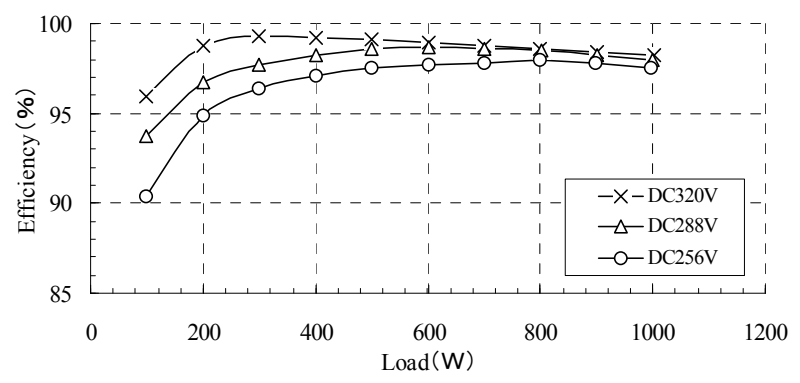

Fig.13. Conversion efficiency in power regenerative mode. 


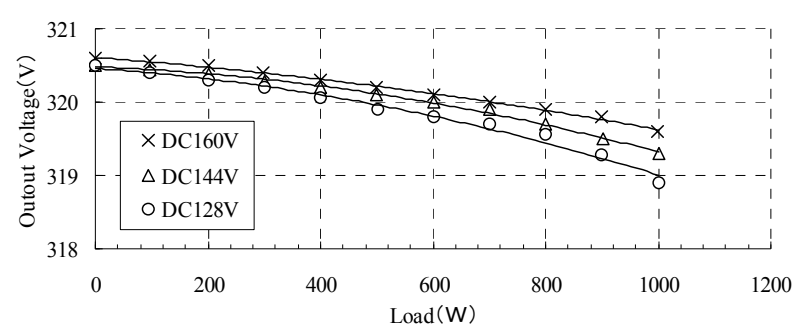

Fig.14. Constant voltage output characteristics of DC voltage $\left(V_{0}\right)$ in power running mode.

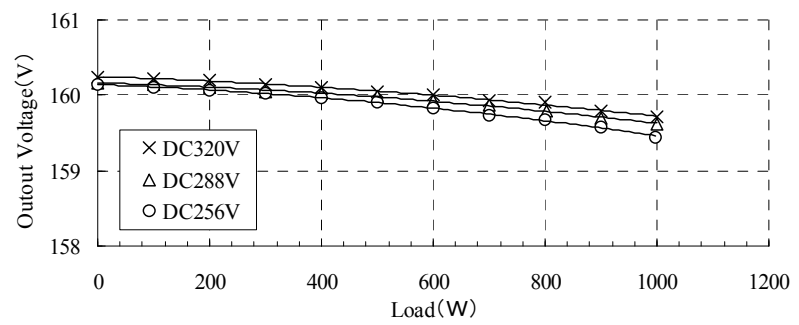

Fig.15. Constant voltage output characteristics of DC voltage $\left(V_{l}\right)$ in power regenerative mode.

Figs. 16 and 17 show output voltage transient property when a steep load fluctuation occurs in power running mode. Non-loaded condition was steeply changed to the rated load $(1 \mathrm{~kW})$; by contrast, the rated load was changed to non-load condition by turning MCB on/off, as shown in Fig. 9. For individual cases, voltage regulation of $1 \%$ against the rated voltage output was obtained. It was found that the proposed converter maintains satisfactory voltage regulation to meet the requirements of power storage devices on the low-voltage side.

\section{CONCLUSION}

Through the performance analysis and evaluation testing, the authors were able to theoretically clarify the superior conversion efficiency of this ac-link bidirectional DC-DC converter equipped with a synchronous rectification function. Further, through feedback control, output stabilization can be achieved. As a result of evaluation testing, in the case of rated output of $1 \mathrm{~kW}$, conversion efficiency of $98.2 \%$ in both power running and regenerative modes, as well as half-loading of $99.1 \%$ were achieved. The future approach will be to carry out a detailed analysis of power losses, and to study appropriate methods to reduce the hard-switching phenomenon.

\section{REFERENCES}

[1] R. W. A. A. De Doneker, D. M. Divan, and M. H. Kheraluwala, "A three-phase soft-switched high-power-density dc/dc converter for highpower applications," IEEE Trans. Ind. Appl., vol. 27, no. 1, pp. 797806, Jan./Feb. 1991.

[2] M. H. Kheraluwala, R. W. Gascoigne, D. M. Divan, and E. D. Baumann, "Performance characterization of a high-power dual active bridge dc-to-dc converter," IEEE Trans. Ind. Appl., vol. 28, no. 6, pp. 1294-1301, Nov./Dec. 1992

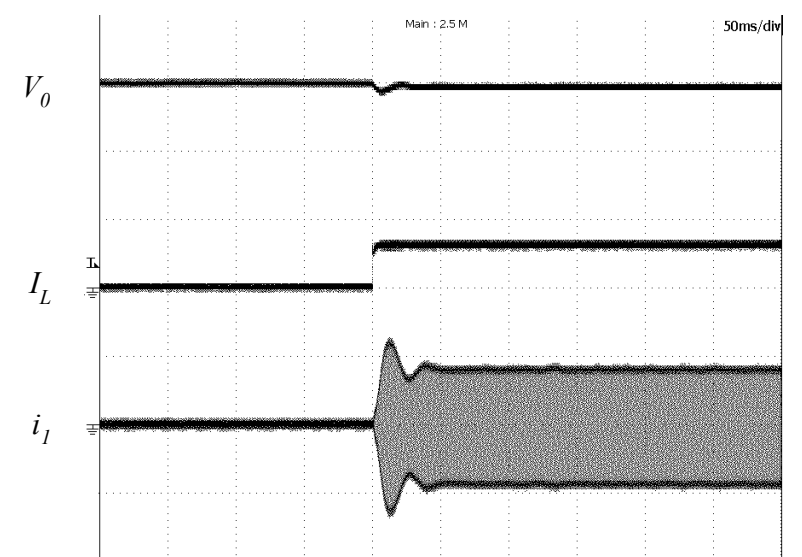

$V_{0}: 20 \mathrm{~V} /$ div., $I_{L}, i_{1}: 5 \mathrm{~A} /$ div., $\mathrm{H}: 5 \mathrm{us} / \mathrm{div}$.

Fig.16. Current/voltage waveforms measured at different locations of converter when steep load fluctuation occurred in power running mode.

$\left(V_{l}=160 \mathrm{~V}, V_{0}=320 \mathrm{~V}, P_{0}: 0 \rightarrow 1 \mathrm{~kW}\right)$

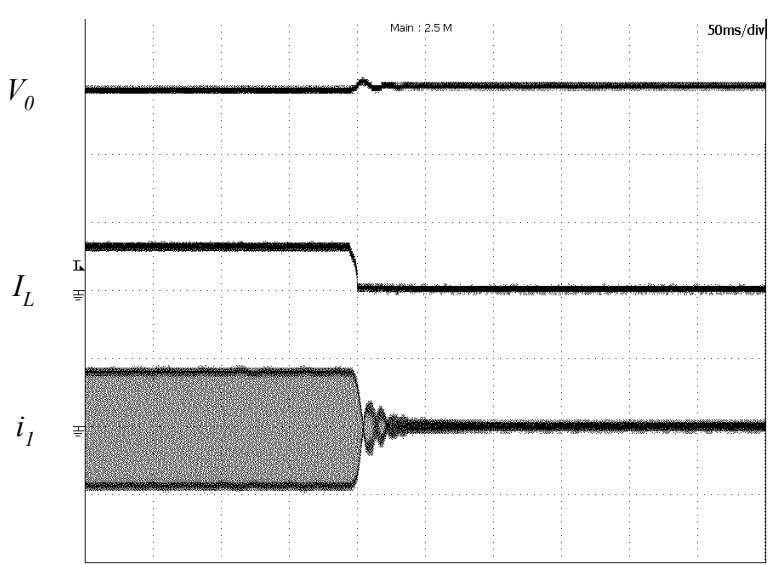

$V_{0}: 20 \mathrm{~V} /$ div., $I_{L}, i_{1}: 5 \mathrm{~A} /$ div., $\mathrm{H}: 5 \mathrm{us} /$ div.

Fig.17. Current/voltage waveforms measured at different locations of converter when steep load fluctuation occurred in power running mode.

$\left(V_{l}=160 \mathrm{~V}, V_{0}=320 \mathrm{~V}, P_{0}: 1 \mathrm{~kW} \rightarrow 0\right)$

[3] S. Inoue and H. Akagi, "A bidirectional isolated dc-dc converter as a core circuit of the next-generation medium-voltage power conversion system," IEEE Trans. Power Electron., vol. 22, no. 2, pp. 535-542, Mar. 2007.

[4] Huang-Jen Chiu and Li-Wei Lin, "A bidirectional dc-dc converter for fuel cell electric vehicle driving system," IEEE Trans. Power Electron., vol. 21, no. 4, pp. 950-958, Jul. 2007.

[5] F. Krismer, J. W. Kolar, "Accurate small-signal model for the digital control of an automotive bidirectional dual active bridge," IEEE Trans. Power Electron., vol. 24, no. 12, pp. 2756-2768, Dec. 2009.

[6] F. Krismer, J. W. Kolar, "Accrate power loss model derivation of a high-current dual active bridge converter for an automotive application," IEEE Trans. Ind. Electron., vol. 57, no. 3, pp. 881-891, Mar. 2010.

[7] S. Inoue and H. Akagi, "A bidirectional dc-dc converter for an energy storage system with galvanic isolation," IEEE Trans. Power Electron., vol. 22 , no. 6 , pp. 2299-2306, Nov. 2007.

[8] T. Hirose, H. Matsuo, Y. Ishizuka, "Development of an independent type of hybrid power generation system," in Proc. IEEE INTELEC, vol.31, pp. 598-602, Oct. 2009

[9] K. Iida, H. Matsuo, T. Hirose, Y. Ishizuka, "A novel bidirectional dc-dc converter with high efficiency and small size ac-link," in Proc. INTELEC, vol.31, pp. 11-18, Oct. 2009.

[10] T. Hirose and H. Matsuo, "A consideration of bidirectional superposed dual active bridge dc-dc converter," in Proc. PEDG, pp. 39-46, Jun. 2010. 